\title{
'Light up for all' Building Knowledge on Universal Design Through Direct User Contact in Design Workshops
}

\author{
Elke Ielegems $^{\mathrm{a}, 1}$, Hubert Froyen ${ }^{\mathrm{a}}$, Jasmien Herssens ${ }^{\mathrm{a}}$ and Jan Vanrie ${ }^{\mathrm{a}}$ \\ ${ }^{a}$ Hasselt University, Martelarenlaan 42, 3500 Hasselt, Belgium
}

\begin{abstract}
For the creation of inclusive design solutions, designers require relevant knowledge about a diversity of users throughout the design process. Besides understanding users' needs and expectations, the ways in which users perceive and experience the environment contain valuable knowledge for designers. Since users' perceptions and experiences are mainly tacit by nature, they are much more difficult to communicate and therefore more difficult to externalize. Hence, more insight is needed into the ways designers can build knowledge on Universal Design through direct user contact.

In a project called 'Light up for all' architecture students are asked to design a light switch and socket, elegant, usable and understandable to the greatest extent possible by everyone. Two workshops with user/experts are organized in the first stages of the design process in which students could gain insight into users' experiences and perceptions through direct contact. Three data collection techniques are used to analyze the teams' design processes: (1) a design diary, (2) observations of the workshops and (3) a focus group.

By means of analyzing collected qualitative data, we have identified three different design aspects that affect designers' UD knowledge building process. First, findings give indications on values and limitations of working with selected design artefacts when externalizing users' experiences. Second, the value of stories clearly affected designers' deeper understanding about users' experiences. Finally, results show that in some situations, designers encountered contradictory information between observations and verbal conversations. These insights may help researchers to better understand designers' process of building knowledge on UD from users' experiences and perceptions, which may result in better incorporating users' experiences when designing for everyone.
\end{abstract}

Keywords. Design process, tacit and explicit knowledge, embodied user knowledge, knowledge building, Universal Design

\section{Introduction}

The social, academic and political field embraces Universal Design (UD), Design for All (DfA) or Inclusive Design (ID) more and more as a strategy to move towards a more sustainable and inclusive world. Demographic changes, the increasingly aging population as well as a drive for equal opportunities result in a continuous search for design that supports everyone, regardless of age, gender, abilities, ethnicity, profession, situation, perceptions or experiences.

${ }^{1}$ Elke Ielegems, Faculty of Architecture and Arts, Hasselt University, Martelarenlaan 42, 3500 Hasselt, Belgium; email: elke.ielegems@uhasselt.be. 
Although the terms Universal Design (UD), Design for All (DfA) and Inclusive Design (ID) have a different background as well as a different geographical origin, their driving goals are very closely related to one another. In this paper, these three terms are therefore considered as synonyms. In line with various authors, we relate UD more to a process than to an objective or final design result [1-5]. Dong [6] nicely phrases this: "If we think 'design' as a process of examining a problem and creating a solution, then 'Universal Design' brings the perspective of real people into the process, inspiring a multitude of viewpoints and innovative ideas." In this regard, the term Universal Desinging, coined by Steinfeld and Tauke [7], clearly articulates this non-stop process with continuous feedback of diverse people.

\subsection{Universal Designing as a process of knowledge building}

Designing is generally seen as a process of design making, leading most often to the design of a product. We will however look at designing - and more specifically at Universal Desinging - as a process of continuously building knowledge on UD $[8,9]$. Next to the process of making, each design process is simultaneously a process in which designers as well as other stakeholders learn about innumerable design aspects. Designers gradually gather knowledge about the nature of the design problem throughout the design process [10]. Looking at the design process from the perspective of a knowledge building process is not new in the domain of, for example, Knowledge Management [e.g., 11, 12]. However, this specific perspective offers opportunities in the domain of UD to focus on the actual exchange of user data, information and knowledge between designers and other stakeholders, and how it affects building knowledge on UD.

"Knowledge on people is essential in order to come up with informed and inspired design interventions" [13]. Designers need to be able to actively interpret user data and information in order to gain personal knowledge that can be integrated in specific design situations [14]. In this respect, little is known about the ways in which designers actually build knowledge on UD throughout the design process and which types of knowledge are important for designers to design more inclusive products, services or buildings. In this paper, we specifically focus on how designers can build knowledge on UD through direct user contact in the context of design workshops with user/experts [15]. In additions, we examine which aspects affect this process of knowledge building. Before elaborating on the experiment that has been set up to examine these issues, it is important to identify knowledge on UD and set our specific research focus within this comprehensive domain.

\section{Knowledge on Universal Design}

\subsection{Learning from users' experiences and perceptions}

When looking at Universal Desinging as a process of building knowledge on UD, it is important to look at which types of knowledge designers need throughout this process. Designers generally tend to focus on learning from hard facts, measurements and requirements that are easy to communicate [16]. However, according to several authors, rich and softer kinds of information on users' experiences and perceptions could help designers to better understand users' backgrounds and to be able to situate this information in a wider context [17-20]. This information is more context-dependent [21], 
not only explaining 'what' or 'how', but also 'why' users experience and perceive the environment the way they do [17]. Learning from people's experiences can serve as a rich source of inspiration and ideation for designers. [22-24].

Sleeswijk Visser and colleagues [25] refer to this issue with the term 'rich experience information', which is “an umbrella term for all factors that influence how a person perceives and feels about the situation he/she is in [...]. The context can include the physical location (objects, temperature, daylight, noise), social factors (who is around and who is not around), cultural factors (values, background) and time" [25]. Pallasmaa addresses similar issues as well, but he refers to the term "embodied experiences' [26-29] and looks at corresponding contextual factors as those defined by Sleeswijk Visser, but from the specific point of view of our senses. Various definitions characterise experiences as situated and holistic [30, 31]. They are very personal, "composed out of tangible (e.g., physical needs, space requirements, ergonomic issues) and intangible (e.g., emotional needs, values) aspects" [31]. This makes users' experiences not easy to extract, although this is crucial in order to design for them [25].

\subsection{Tacit and explicit knowledge as an intertwining knowledge spectrum}

There are many views on knowledge and on knowledge types [32], such as propositional knowledge, procedural knowledge, episodic knowledge, experiential knowledge, declarative, knowledge, codified knowledge, tacit and explicit knowledge, transferable knowledge... [e.g., 10, 21, 33, 34-37]. Some of them overlap in meaning and others have various synonyms, which makes it rather confusing to understand the concept of knowledge in general [38], and design knowledge in particular. However, which knowledge types are important when building knowledge on UD for the specific purpose of learning from users' experiences and perceptions through direct user contact?

In this paper, we will focus on one of the knowledge pairs that appear to be crucial for building knowledge on UD [39], namely tacit and explicit knowledge. Explicit knowledge is easy to verbalize and to communicate with others. Tacit knowing is more intuitive, unarticulated by nature [35] and much more difficult to capture or reveal than explicit knowledge [34]. Polanyi [35] describes tacit knowing as follows: "We know more than we can tell". The knowing is in the action itself by "intelligently doing something in an intuitive manner" [40]. For example, "knowledge tied to the senses, tactile experiences, movement skills, intuition, unarticulated mental models, or implicit rules of thumb is tacit" [41]. The knowing is deeply rooted in people's actions, experiences and values, or as Schön [42] puts it, it is the knowing-in-action which is mainly tacit by nature.

Interestingly, literature shows how knowledge will most likely exist out of a combination of tacit as well as explicit knowledge, instead of entirely being tacit or explicit. This is also addressed by Hildreth and Kimble [43] as 'the duality of knowledge'. A scheme developed by Wong and Radcliffe [44] nicely shows how each 'knowledge piece' contains a varying level of tacit as well as explicit knowledge. 


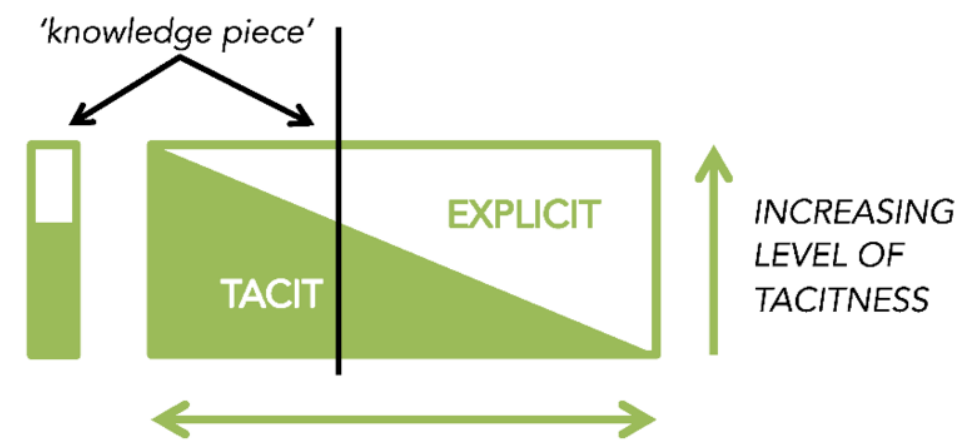

KNOWLEDGE SPECTRUM

Figure 1. Spectrum of explicitness/tacitness of knowledge, adapted from Wong \& Radcliffe (2000).

As shown on this figure, knowledge may include partially tacit as well as explicit knowledge. Thus, when we speak of tacit or explicit knowledge, we refer to the main type of knowledge in the action or experience although both knowledge types are most probably inherently present. When looking at this figure from the perspective of knowledge on people's more deeply rooted experiences or perceptions, they are more tacit in nature and thus situated at the left part of the figure.

\subsection{Externalizing tacit knowledge}

In previous paragraphs, we have argued how people's experiences and perceptions are mainly tacit by nature. For the purpose of gaining more insight into how designers building knowledge on people's experiences and perceptions, the question is raised if tacit knowledge can be externalised. Although some researchers argue that tacit knowledge cannot be made explicit, most research points out that it is possible to make tacit knowing at least partially explicit in order to learn from it [22, 25, 45, 46].

Polanyi nuances both views by stating that tacit knowing can become explicit to a certain degree, but explicit knowledge cannot completely replace its counterpart. He uses the example of the skills of a driver. You cannot learn how to drive by only getting the theory, without doing and experiencing the act of driving yourself. A similar example more closely linked to designing for diversity deals with exploring a new space without sight. Some people who are blind often orient themselves by means of a cane, using it to explore a new space in order to get familiarized with that space. They have learned how to make meaning of what they feel at the tip of the cane through experience. When teaching this technique to people who are not used to handling a cane or exploring a room without sight, this is very difficult to articulate [35]. Consequently, a lot of training and an extended learning experience may be necessary since this ability is mainly tacit by nature [47]. However, as Wong and Radcliffe argue, some parts of this knowledge can also be made explicit. This can be demonstrated by looking at existing published research (which is per definition explicit). For example, researchers have externalized tacit knowledge by studying how people who are blind explore spaces and found, for example, different patterns in the routes used by blind people [e.g., 48, 49, 50]. The two examples above show how, in line with Polanyi's reasoning, mainly tacit knowledge in people's experiences and perceptions can be externalized, although a part will remain difficult to make explicit. 
This leaves us with the following question: How can tacit knowledge be externalized? Stappers and Sanders [22, 51], for example, discuss various research techniques to externalize tacit and even latent needs, such as generative techniques or observations. The use of design artefacts are interesting as well to discuss as a way to elicit tacit knowledge. Design artefacts are often central to the design process. The use of design artefacts is diverse as well as endless, and its importance is generally clearly acknowledged [52, 53]. Design artefacts tend to be rich in meaning [54]; and when interacting with other stakeholders, they can be used, for example, to mediate understanding, to distribute information, to get input from different stakeholders, to discuss design problems, to explore solutions, to keep a legitimate record of the decisionmaking process... [55-58]. Since design artefacts are found to be very suited to examine how tacit and explicit knowledge is developed, translated and exchanged [59], they are invaluable to investigate designers' knowledge building process as important 'artefacts of knowing' [59].

\section{Set-up design workshops 'Light Up for all'}

\subsection{Research Methodology}

An experiment was set up to study how designers build knowledge on UD through direct user contact in design workshops. Eleven second year bachelor architecture students (7 female -4 male) between 19 and 21 years old at the time of the experiment, participated in this project. None of the design students had preceding knowledge on UD, neither theoretical knowledge nor practical experience. Since it was new to them, an introduction on the theory behind UD was given next to explaining the design task. Students were divided into two groups of five and six students (resp. group 1 and group 2). Within the timeframe of thirteen weeks, design students were asked to design an inclusive light switch and socket. Workshops took place in a UD Living Lab in Hasselt, Belgium [60] since different light switches and sockets could be tested there. Both design teams were given the same design task and initial information at the start of the design process. They were both asked to organize three workshops:

- Workshop 1: simulation workshop

- Workshop 2: workshop with user/experts

- Workshop 3: workshop with user/experts

Although the three workshops were mandatory, design students were free to fill them in themselves. Thus, a guiding frame was given to them as well as specific dates to organize the three workshops, but the ways in which design students approached every step was open for own interpretation. This guiding frame was necessary to ensure that both design teams had direct user contact. Moreover, by organizing the workshops in a controlled setting and time frame, conditions for observation could be optimized. The following scheme gives an overview of the participants in workshops two and three, consisting of eleven user/experts and two master students Occupational Therapy. The latter supported the other user/experts and participated in the workshops from the perspective of other user groups that were not present at that time. In line with Ostroff, the terms 'user/expert' is defined here as people who have "developed natural experience 
in dealing with the challenges of our built environment. [...] These diverse people have developed strategies for coping with the barriers and hazards they encounter everyday. The experience of the user/expert is usually in strong contrast to the life experience of most designers [...] [15]."

Table 1. Overview of participants in workshops two and three.

\begin{tabular}{|c|c|c|c|c|c|c|c|c|}
\hline CODE & age & gender & profession & relevant expertise & $\begin{array}{l}\text { workshop } 2 \text { - } \\
\text { group } 1\end{array}$ & $\begin{array}{l}\text { workshop } 2 . \\
\text { group } 2\end{array}$ & $\begin{array}{l}\text { workshop } 3 \text { - } \\
\text { group } 1\end{array}$ & $\begin{array}{c}\text { workshop } 3 \\
\text { group } 2\end{array}$ \\
\hline 23-M1 & 63 & $M$ & $\begin{array}{c}\text { industrial } \\
\text { advertisement }\end{array}$ & blindness $100 \%$ & $x$ & & $x$ & $x$ \\
\hline 23-M2 & 28 & $M$ & volunteer & $\begin{array}{l}\text { electric wheelchair user - } \\
\text { reduced motion skills - } \\
\text { balance disturbance - } \\
\text { impaired hearing }\end{array}$ & $x$ & & $x$ & $x$ \\
\hline $23-\mathrm{F} 3$ & 23 & $F$ & student & $\begin{array}{c}\text { master student } \\
\text { occupational therapy }\end{array}$ & $x$ & & $x$ & $x$ \\
\hline 23-F4 & 22 & $\mathrm{~F}$ & student & $\begin{array}{c}\text { master student } \\
\text { occupational therapy }\end{array}$ & & $x$ & $x$ & $x$ \\
\hline 2-M5 & 74 & M & retired & blindness $100 \%$ & & $x$ & & \\
\hline $2-\mathrm{F} 6$ & 7 & $\mathrm{~F}$ & student & child & & $x$ & & \\
\hline $2-\mathrm{F} 7$ & 46 & $\mathrm{~F}$ & employee & adult & & $x$ & & \\
\hline 2-M8 & 79 & $M$ & retired & $\begin{array}{c}\text { senior - tremor - impaired } \\
\text { hearing left }\end{array}$ & & $\mathrm{x}$ & & \\
\hline 2-F9 & 73 & $\mathrm{~F}$ & retired & senior & & $x$ & & \\
\hline 3-M5 & 51 & M & I & $\begin{array}{l}\text { blindness with residual } \\
\text { vision of } 10 \% \text { at right side }\end{array}$ & & & $x$ & $x$ \\
\hline $3-\mathrm{F} 6$ & 39 & $\mathrm{~F}$ & I & blindness $100 \%$ & & & $x$ & $x$ \\
\hline $3-F 7$ & 20 & $\mathrm{~F}$ & student & broken hand - left & & & $x$ & $x$ \\
\hline $3-F 8$ & 76 & $\mathrm{~F}$ & retired & senior & & & $x$ & $x$ \\
\hline
\end{tabular}

\subsection{Collecting Research Data}

Different data sources were used to enhance data credibility [61] and to gain insight into students' design activities inside as well as outside workshops:

- direct observations of workshops

- design artefacts

- $\quad$ personal design diaries

- focus group with design teams

Observing and analyzing stakeholders' design conversations and actions play a central part when examining the UD knowledge building process. In addition, design artefacts are a rich source of data as well to exchange knowledge and information between participants and designers [58, 62]. All design artefacts used throughout the design process were collected, registered and analyzed. In addition, the design diary is found to be an effective technique, specifically to elicit certain aspects of one's own 
design activity amenable to verbal articulation [63]. For this research, design students were asked to make notes and/or draw during the entire design process in a personal 'Light-up-my-day book'.

Finally, 2 focus group groups (i.e., one with group 1 and one with group 2) were conducted at the end of the design process in order to check and verify the researcher's interpretations of gathered research data. Furthermore, it allowed the researcher to go into detail on issues mentioned by one or more students [61]. As such, a rich scale of data sources could be gathered to investigate designers' knowledge building process from different perspectives.

\section{Results}

Before we could analyze the results of this study regarding our research questions, it was important to investigate whether the final design results of the two design teams actually integrate inclusive design elements. Results of this analysis show that design students consciously aimed at enhancing diverse users' capabilities, since sensory, cognitive as well as motion capabilities were represented in the different design outcomes. However, this analysis is not the primary focus of this paper and will not be further discussed here. In this paper, we focus on the ways designers build knowledge on UD through direct user contact in design workshops. Findings show three specific aspects that appeared to be decisive here when building knowledge on UD. Each of these aspects will be discussed in the following paragraphs.

\subsection{Design artefacts as crucial reference point for designers and users}

In this particular experiment, it was important that designers shared and developed ideas with user/experts for the specific purpose of gaining insight into diverse users' experiences and perceptions regarding an inclusive light switch and socket. When analyzing research data, design artefacts appeared to be central in the communication with user/experts throughout the design process. Interestingly, two-dimensional plans or other types of drawings, which are often applied in traditional design processes [53, 64], were not used for communication with user/experts throughout the design process. Students seemed to consider drawings as less useful when actively testing users' experiences. The interaction with children, older people, people who are blind... stimulated them to apply other types of design artefacts. Design students developed quite an amount of design artefacts especially considering the short timeframe (i.e., thirteen weeks).

Figures 2 and 3 give an overview of the design artefacts that were used by the two design teams to learn from user/experts in each stage of the design process. The arrows on the overview show how information led to new design artefacts in which this information was processed. 


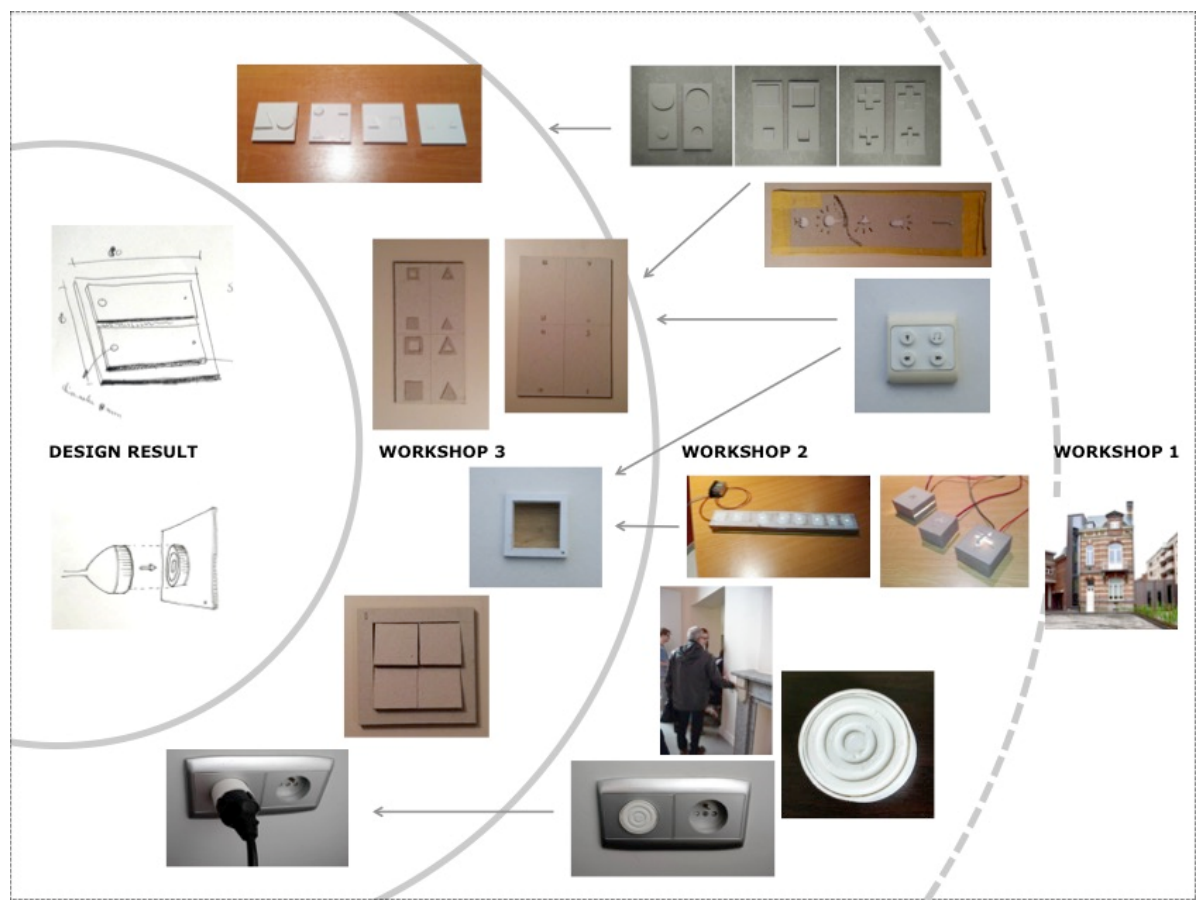

Figure 2. Overview design artefacts, group 1.

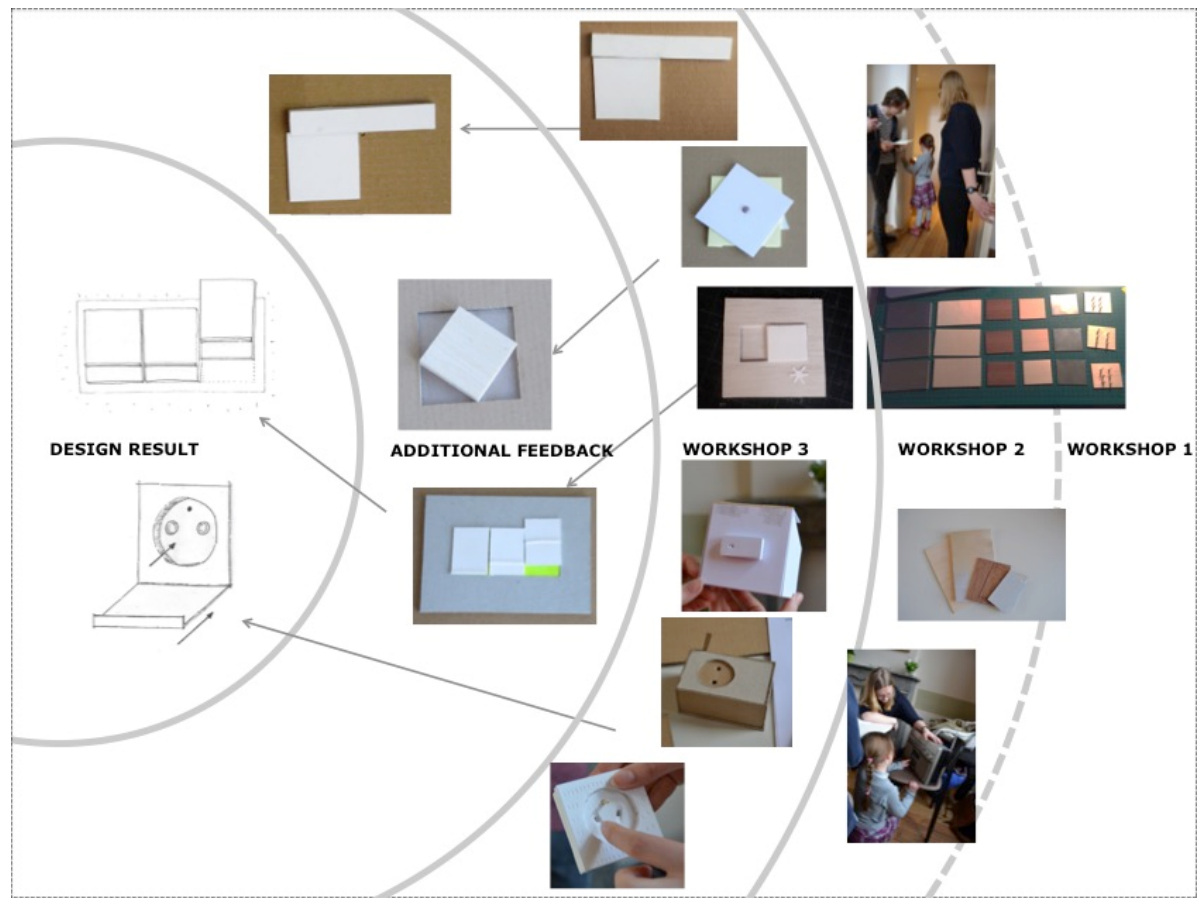

Figure 3. Overview design artefacts, group 2. 
These figures 2 and 3 show how both design teams focused on two specific types of artefacts, namely prototype ${ }^{2}$ and fragment-models ${ }^{3}$. Design teams considered both types of design artefacts to be very valuable to gain information and knowledge from participants. Most fragment-models aimed at answering very specific questions, such as: What size of symbols is useful for you? What form of symbols is useful from a visual and haptic perspective? Which degree of light intensity do you prefer? ... Scale models were not used. It may be assumed that there was no need to use scale models because of the small scale of light switches and sockets.

Design students indicated that the use of design models (in this case, prototypes and fragment-models) helped them to gain useful information from user/experts directly linked to a specific design.

"I think we have gained most information through the use of
design models. We then knew instantly what was possible for
people and what not; What do they value or find important [...]
People directly told us their experiences and perceptions. This
helped us to move on to a next [adapted] design model".

Various examples show how the use of prototypes and fragment-models provided participants with the means to discuss their experiences, which were often difficult, or even impossible, to discuss without any reference point. We will illustrate this with two examples in which design artefacts acted as an invaluable point of reference for both designers and participants. The first example deals with a prototype and the second example with a fragment-model.

Group 2 showed a prototype of a socket in workshop three (see Figure 4). It had grooves intending to support people to slide the pins of the socket into the two holes, since this appeared to be a problem for many people, according to students' findings in workshops one and two. Although the idea was very difficult to verbally describe, user/experts directly understood students' intentions when seeing the prototype. User/experts could immediately experience its use. One person with reduced strength and motion capabilities (23-M2) still experienced difficulties placing the pins in the two holes, despite the additional grooves. However, together with the user/experts, the design team came up with the idea of funnel-shaped openings instead of grooves, which appeared to be a good solution for all participating user/experts. Thus, although design students tried to come up with a solution for a very relevant issue, their design translation appeared to be not suitable for all. By directly testing this, design students got very focused feedback on this aspect. Students of group 2 did not only understand afterwards how they misinterpreted the collected user information from workshops one and two, they also found a suitable, more inclusive solution for all participating user/experts.

\footnotetext{
2 The term 'prototype' is used to refer to models of full-scale products.

3 To the best of our knowledge, we did not find an appropriate term to describe design models of a specific part of the design, meaning a model that focuses on one design element in particular (e.g. symbols, light intensity...) Since this difference is important for our analysis, we will use the term 'fragment-model' here.
} 


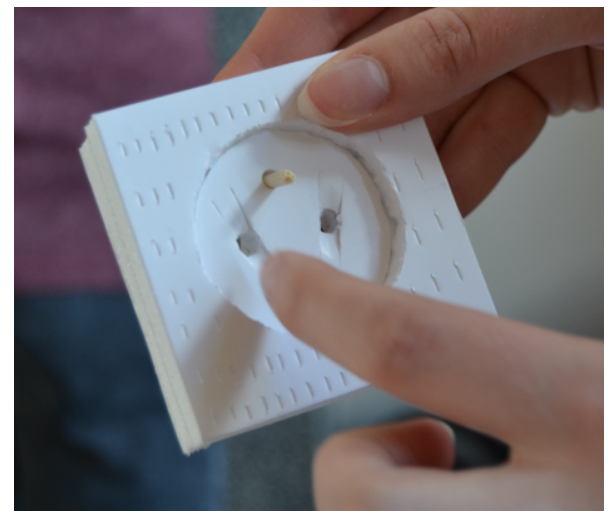

Figure 4: Prototype of a socket shown in workshop three - group 2.

The second example deals with the development of various fragment-models regarding 'lighting' in workshop two by group 1 (see Figure 5). One of these models examined different ways of integrating lighting: (1) indirect light coming from aside, (2) indirect light accentuating a symbol and (3) direct light in the form of a symbol. Mock-ups were tested in different situations: light and dark rooms, looking at the fragment-models from a close or further distance... Participants could instantly experience what was best for them. When students would have discussed this issue without any design artefact, it would have been much harder for user/experts to give effective feedback. Here too, a reference point was indispensable to compare users' personal experiences. In the end, students learned that user/experts preferred indirect lighting to be able to locate the light switch. However, all three fragment-models were experienced as too bright. User/experts preferred more subtle light. Especially in darker rooms when they wanted to sleep this light was experienced as 'disturbing' by user/experts.
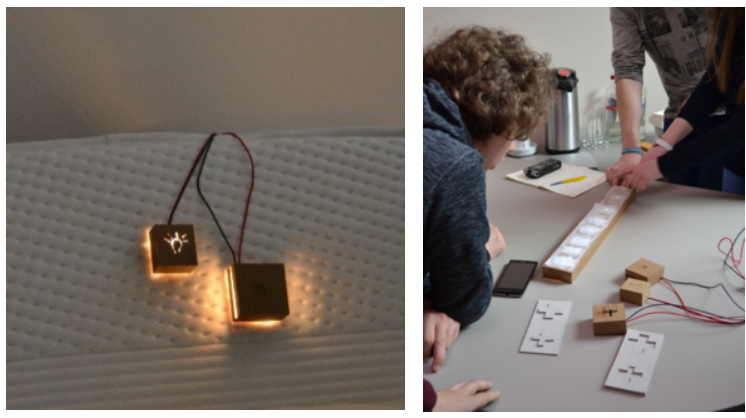

Figure 5: Fragment-models regarding to light in workshop two - group 1.

These two examples show that participants immediately understood what designers wanted to know by means of a tangible design artefact. On the one hand, the prototypes and fragment-models provided the information needed to share these ideas. This understanding was crucial for user/experts to be able to give efficient feedback. Moreover, user/experts had a clear reference point, a kind of basic starting point, to refer to when describing their highly personal experiences, which are difficult to express. They could feel, see or try them out. This way, the artefacts acted as a starting point to refer to 
for user/experts when giving feedback to design students. Thus, it considerably helped participants to transfer knowledge and information to the design students.

For design students on the other hand, prototypes as well as fragment-models helped to directly relate to users' feedback. This was especially the case for prototypes, as indicated by one of the students. Since user/experts could demonstrate what did or did not work for them and by actually performing, design students seemed to better comprehend participants' feedback. Moreover, this user feedback tended to be much more focused, which helped designers to get more useful and directly translatable information. However, this focused information may also have its limitations, since important aspects may be forgotten or left out of the discussion. For example, if a specific prototype did not function for someone, it seemed to be much harder to get additional feedback on other design elements of the prototype (e.g., texture, symbols, size..., researcher's observations). These elements may have been not useful for that specific design, but it would have been usable information for other designs.

\subsection{Value of stories about personal experiences to understand underlying reasoning}

During workshops two and three, several user/experts told 'personal stories' to explain issues they needed to conquer in their daily lives concerning light switches and sockets. Most of the time, this occurred when user/experts where triggered by specific design artefacts. In various stories the embodied experience in relation to space (and in this case the discussed object) was central. Describing past experiences (i.e., memories), whether positive or negative, appeared to give design students more insight into how user/experts experienced their environment. For example, the following personal story was told by a user/expert who is blind (2-M5) and described afterwards by one of the design students:

"Many things, amongst which light switches and sockets, seem so self-evident for me while it sometimes is not as useful for some as I expected. For example, a person who is blind [told] that he often switched the light on without noticing what he did.

This is why he did not want to have push buttons unless they clearly indicate if the lights are on or off. [...] Afterwards, this may seem very logic, but it is so easy to forget these people [...] throughout the design process."

This experience was confirmed by other visually impaired user/experts during workshops two and three (2-F9, 3-F6). For example, another user/expert (3-F6) described a similar situation. She did not know that the light was off while she was sitting in the living room. When people entered the room, they did not expect somebody to be there. Consequently, she appeared to unwillingly scare people since she was sitting there quietly in the dark. The memory of situations in which user/experts did not know if the lights were on or off was experienced as being 'frustrating' for the consulted blind user/experts. The examples above and other analyzed research data clearly indicated how both design teams highly valued this kind of information. These personal stories appeared to work as an eye opener for design students to better understand the true impact of design on users' daily lives, even for such a small design element as a light switch or a socket. 
Through this personal story indicating how the participating blind user/expert struggled with knowing if the lights were on or off, it became clear to students that people who are blind did not experience push buttons as inclusive. In addition, they learned how standard light switches do not offer sufficient information for people who are blind since haptic properties for knowing if the light is on/off are generally absent. Consequently, both design teams focused in their final design proposals on the possibility to know whether the light is on or off without sight (see final design proposal in figures 1 and 2). Group 1 responded to this by making a light switch that always goes off when pushing on the lower side of the button and always goes on when pushing the upper side. Moreover, symbols indicate which side is on or off. Group 2 designed a sliding system where it is clear when the light is on or off by seeing and feeling the position of the switch. This personal story clearly clarified to both design teams why user/experts who are blind disliked push buttons. A better understanding of these 'why-questions' through personal stories clarified the actual design problem, as confirmed by other studies [e.g., 17]. As such, comprehension of underlying reasoning in users' feedback resulted for both design teams in an effective design translation.

The example given may be more related to explicit than to tacit user information. However Luck [65] indicates that descriptive narratives-described here as personal stories - also contribute to elicit tacit knowledge and to allow designers to gain insight into users' mindset: "When an individual shares their personal perceptions, which are based on their experience this can give the designer insight into the factors that influence a disabled person's experience of an environment" [65]. Thus, personal stories do not show embodied users' experiences as knowledge-in-action, but they do enable designers to elicit tacit and explicit knowledge from users' past daily life experiences-

\subsection{Influence of habitual actions on building knowledge on UD}

Analysis of the experiment shows a third aspect that was decisive when building knowledge on UD, namely users' habitual actions and memories. In contrast to two previous aspects, this third aspect deals with pitfalls when building knowledge on UD through direct user contact. Most people are very familiar with how light switches and sockets generally look like and how they are used. People are trained from early childhood to use them, without really questioning their usability or comfort. They have created their own image and their own habits for using them. Design students experienced several situations in which these habits and memories considerably affected the knowledge transfer process in different ways. We will highlight two examples in which habitual habits and memories played a crucial role in design students' knowledge building process.

\subsubsection{Critically observing habitual actions}

Throughout the design process, several situations occurred in which the design team's critical reflection was required regarding participants' habitual actions. In this example, there was a gap between users' actions and their verbal feedback. After workshop two, group 2 asked additional user feedback in a residential care center to decide which of the three improved prototypes would be chosen as a final design result and to make final changes to the chosen prototype. Design students intentionally did not want to explain their prototypes to user/experts of the residential care center in order to first observe how they used them. In doing so, they noticed that people instinctively started pushing the 
buttons of two prototypes (see Figure 6) while they were actually turning buttons. The system to use these prototypes was not clear to the users. Users' actions provided design students with clear indications that the prototypes were not intuitive in use. Interestingly, when asking afterwards which prototype user/experts preferred, they answered that all three models were equally good and they were all easy to use. Since actions and answers were contradicting, students critically reflected on user/experts' feedback, concluding that users' answers were probably 'socially desirable answers' towards the design students (which the people of the residential care center did not know and only shortly met). Therefore, the choice for the final design was not based on users' verbal feedback, but on design students' observations of users' habitual performances. If the design team would have only relied on users' explicit answers, they may have concluded that all three prototypes fulfilled users' needs. Thus, in this situation, design students learned more from critically observing users' habitual actions, which gave useful information on the intuitive use of the prototypes.

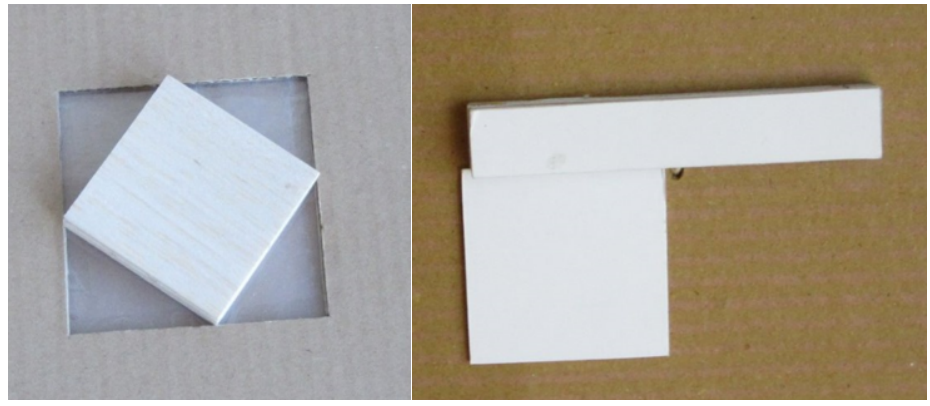

Figure 6. Design artefacts - group 2.

This example shows how users' habits affected designers' knowledge building process. Design students' critical reflection and conscious interpretation of users' feedback helped to draw conclusions. Knowledge gained by means of observations considerably influenced the decision-making process and led the design team to another design result than when only relying on explicit information expressed by user/experts. Observations are generally valued as a useful method to gain information and knowledge about users [66]. Students acknowledged that observations helped them to elicit more embodied user experiences in different situations throughout the design process and, in this case, it gave them additional interesting information on the usability and intuitive use of products.

\subsubsection{Habitual actions and out-of-the-box thinking}

We have already indicated how familiar actions (i.e., turning on the light) influence the way people understand and use the environment. In addition, the analysis shows how design students experienced that the choice for a type of design artefact influenced users' capability to think out-of-the-box. For example, group 2 made use of existing light switches and sockets to gain general insight into people's experiences. When discussing these existing, already familiar products with user/experts, it appeared to be more difficult to discuss other deviating or innovative ideas. One student explained how users were "restrained to think about other possibilities"; moreover "they were more focused on what already existed". 
In addition, not all user/experts appeared to be critical about their experience with familiar products, according to the design students. Most of the user/experts from group 2 experienced a traditional socket as a usable product that did not need specific improvements. One student indicated that "many participants preferred the current light switch to push because it is used almost everywhere. However, this light switch is not ideal for everyone". As such, some users' feedback was in contrast to students' own experiences as well as to their observations. Students therefore presumed that participants may have reacted this way because these actions have become a habit to them or they did not critically reflect how it could be different since they have always known this type of socket. This example confirms how designers needed to critically reflect on the reasoning behind people's feedback. In addition, it shows that designers need to be aware that using familiar design artefacts - in this case existing light switches and sockets - may hold people back from thinking more critically and out-of-the-box. Nevertheless, students indicated as well that these artefacts helped them to gain more general insight into different design elements at the start of the design process.

\section{Discussion and conclusions}

In this paper, we have looked at UDing as a process of building knowledge on UD through direct user contact. We have examined the ways in which designers can build knowledge from diverse users' experiences and perceptions and, more specifically, which aspects affect this knowledge building process. Before elaborating on the conclusions, it is important to emphasize that this experiment in which two design workshops with user/experts were organized, has taken place in an educational setting with bachelor architecture students who had no preceding knowledge of UD. This particular context needs to be considered when interpreting the results of this paper.

Findings show different influential aspects, namely (1) 'artefacts of knowing' as a crucial reference point, (2) the value of stories on designers' deeper understanding and (3) the influence of habitual actions which require designers to think critically when building knowledge on UD. When bringing findings from this study together, we can draw some initial conclusions. Design artefacts, which are central in designers' daily design practice [59], have a huge impact on the process of building as well as sharing knowledge on UD. Findings suggest that well-chosen design artefacts can act as a strong shared design language. They can improve the inclusion of exchanging knowledge between, in this case, design teams and participants of the design workshops. In particular in the field of co-designing, the concept of a shared design language has been identified in the literature as a strong tool that can be used by designers/researchers and stakeholders to communicate with one another [19, 51, 67]. An understandable design language can support users to comprehend the design and how design solutions meet diverse users' requirements and aspirations. The better users understand the design proposals, the better they can react and give useful and effective feedback to the design teams. In the experiment, design artefacts clearly act as an essential reference point for designers as well as users to evaluate and discuss experiences which are often hard to communicate. For example, the fragment-model was crucial to gain knowledge about user/experts' most comfortable level of light intensity. Design artefacts can serve as a trigger to reveal users' understanding and knowledge, which consequently helps to make the design more meaningful for users as well as other stakeholders [58]. 
In addition, designers truly valued stories in which users explained their experiences and feelings. These stories helped them to gain a deeper understanding of users' experiences. In the experiment, the stories were often related to design artefacts. Luck and colleagues [58, 62, 68, 69], who mainly focus in their research on the social process as an essential part of the design process, argue how knowledge and understanding can be gained when communicating about design artefacts through the use of talk as well as gestures. This is also acknowledged in early work from a.o. Cross and colleagues in which they show how drawing and talking together enable the design process to work [70]. We add that, next to this strong link between design artefacts and a meaningful conversation, a critical observation is an essential part to building knowledge on UD through direct user contact. Some types of design artefacts require critical thinking from the designers, since they negatively influence users' ability to, for example, think-outof-the box. This too, is important when choosing the types of design artefact to use throughout the design process. The selection of suited design artefacts therefore needs to be actively considered throughout design processes, and UD processes in particular. Combining knowledge and information from these three different perspectives helps designers to come up with funded design decisions and knowledge on UD. These insights may direct designers as well as researchers in better incorporating users' experiences when designing for everyone.

\section{References}

[1] E. Ielegems, J. Herssens, and J. Vanrie, "An inclusive design model supporting interaction between designer and user," in Proceedings of the 20th International Conference on Engineering Design (ICED 2015) Design for life, Milano, Italy, 2015, vol. 9, pp. 259-269.

[2] S. Iwarsson and A. Ståhl, "Accessibility, usability and universal design — positioning and definition of concepts describing person-environment relationships," Disability and rehabilitation, vol. 25 , no. 2 , pp. 57-66, 2003.

[3] World Health Organisation (WHO), "Chapter 6: Enabling environments," in "World report on disability," 2011. [Online]. Available: http://www.who.int/disabilities/world_report/2011/report/en/

[4] E. Steinfeld and J. Maisel, Universal design: Creating inclusive environments. Hoboken, New Jersey: John Wiley \& Sons, 2012.

[5] E. Ielegems and H. Froyen, "Universal Design, A Methodological Approach," Journal of Accessibility and Design for All, vol. 9, no. 10, pp. 31-42, 2014.

[6] H. Dong, "Global Perspectives and Reflections," in Trends in Universal Design. Norway: Norwegian Directorate for Children, Youth and Family Affairs, The Delta Center, 2013, p. 38.

[7] E. Steinfeld and B. Tauke, "Universal designing," Universal design, vol. 17, pp. 165-190, 2002.

[8] S. Evenson and H. Dubberly, "Design as learning — or "knowledge creation"- the SECI model," Interactions Magazine, vol. 18, no. 2, pp. 1-6, 2011.

[9] P. Bertola and J. C. Teixeira, "Design as a knowledge agent: How design as a knowledge process is embedded into organizations to foster innovation," Design Studies, vol. 24, no. 2, pp. 181-194, 2003.

[10] B. Lawson and K. Dorst, Design expertise. Oxford: Elsevier Ltd., 2009, p. 321.

[11] M. Fenker, "Design and management of building as learning processes " in Joint CIB W070, W092, TG72 International Conference: Delivering Value to The Community, Cape Town, South Africa, K. MIchell, P. Bowen, and K. Cattel, Eds., 2012: Department of Construction Economics and Management, pp. 234-240.

[12] Y. Fu Qiu, Y. Ping Chui, and M. G. Helander, "Cognitive understanding of knowledge processing and modeling in design," Journal of Knowledge Management, vol. 12, no. 2, pp. 156-168, 2008.

[13] F. Nickpour, "Public engagement with inclusive design: a platform for co-design with people," Design for All, vol. 5, no. 6, pp. 26-35, 2010.

[14] J.-H. Woo, M. J. Clayton, R. E. Johnson, B. E. Flores, and C. Ellis, "Dynamic Knowledge Map: reusing experts' tacit knowledge in the AEC industry," Automation in construction, vol. 13, no. 2, 
pp. 203-207, 2004. [Online]. Available:

http://www.sciencedirect.com/science/article/pii/S0926580503001067.

[15] E. Ostroff, "Mining our natural resources: The user as expert," Innovation, the Quarterly Journal of Industrial Designers Society of America, vol. 16, no. 1, p. 33, 1997.

[16] E. Ielegems, J. Herssens, E. Nuyts, and J. Vanrie, "Drivers and Barriers for Universal Designing: A Survey on Architects' Perceptions," Journal of Architectural and Planning Research, vol. 36, no. 3, pp. 181-197, 2019.

[17] Ö. D. Buskermolen, J. Terken, and B. Eggen, "Informing user experience design about users: Insights from practice," in CHI'12 Extended Abstracts on Human Factors in Computing Systems, 2012: ACM, pp. 1757-1762.

[18] V. Van der Linden, I. Van Steenwinkel, H. Dong, and A. Heylighen, "Designing "little worlds" in Walnut Park: How architects adopted an ethnographic case study on living with dementia," in Design + Research + Society. Future-Focused Thinking, 2016: Design Research Society.

[19] F. Sleeswijk Visser, P. J. Stappers, R. Van der Lugt, and E. B. Sanders, "Contextmapping: experiences from practice," CoDesign, vol. 1, no. 2, pp. 119-149, 2005.

[20] M. Strickfaden and P. Devlieger, "Empathy through accumulating techne: Designing an accessible metro," The Design Journal, vol. 14, no. 2, pp. 207-229, 2011.

[21] I. M. Kirkeby, "Accessible Knowledge-Knowledge on Accessibility," Journal of Civil Engineering and Architecture, 2015.

[22] E. B.-N. Sanders, "From user-centered to participatory design approaches," Design and the social sciences: Making connections, pp. 1-8, 2002.

[23] E. C. O'Shea, S. Pavia, M. Dyer, G. Craddock, and N. Murphy, "Measuring the design of empathetic buildings: a review of universal design evaluation methods.," Disability and Rehabilitation: Assistive Technology, vol. 11, no. 1, pp. 13-21, 2014.

[24] A. Lukman, C. Bridge, S. Dain, and M.-Y. Boon, "Developing Perception-Based Criteria of Inclusive (Architectural) Design," in Proceedings of the International Conference On Universal Design, 2014, pp. 109-118.

[25] F. Sleeswijk Visser, "Bringing the everyday life of people into design (doctoral dissertation)," Technische Universiteit Delft, 2009.

[26] J. Pallasmaa, "Lived Space. Embodied Experience and Sensory Thought," Oase: The Visible and the Invisible, vol. 58, no. 5, pp. 13-34, 2002.

[27] J. Pallasmaa, The embodied image: imagination and imagery in architecture. Wiley Chichester, 2011.

[28] J. Pallasmaa, "Empathic imagination: Formal and experiential projection," Architectural Design, vol. 84 , no. 5 , pp. 80-85, 2014.

[29] J. Pallasmaa, The eyes of the skin. Chichister: Wiley Acadamy, 2005. 1996.

[30] J. Dewey, "Having an experience," Art as experience, pp. 36-59, 1934.

[31] I. Oygur and J. M. McCoy, "User: Inspiration or Constraint?," Journal of Interior Design, vol. 36, no. 3, pp. 1-13, 2011.

[32] J. Bashouri and G. William Duncan, "A model for sharing knowledge in architectural firms," Construction Innovation, vol. 14, no. 2, pp. 168-185, 2014.

[33] K. Niedderer, "Mapping the meaning of knowledge in design research," Design Research Quarterly, 2007.

[34] I. Nonaka, "A dynamic theory of organizational knowledge creation," Organization science, vol. 5, no. 1, pp. 14-37, 1994.

[35] M. Polanyi, The tacit dimension. London: The University of Chicago Press, 1967.

[36] M. Alavi and D. E. Leidner, "Review: Knowledge management and knowledge management systems: Conceptual foundations and research issues," MIS quarterly, pp. 107-136, 2001.

[37] I. M. Kirkeby, "Transferable knowledge: an interview with Bent Flyvbjerg," Architectural Research Quarterly, vol. 15, no. 01, pp. 9-14, 2011.

[38] M. Jakubik, "Exploring the knowledge landscape: four emerging views of knowledge," Journal of knowledge management, vol. 11, no. 4, pp. 6-19, 2007.

[39] E. Ielegems, J. Herssens, and J. Vanrie, "User Knowledge Creation in Universal Design Processes," in Proceedings of the Ahfe 2016. International Conference on Design for Inclusion, Orlando, Florida, G. Di Bucchianico and P. Kercher, Eds., July 27-31, 2016 2016, vol. 500 : Springer, 2016, pp. 141-154.

[40] N. Nimkulrat, K. Niedderer, and M. Evans, "On Understanding Expertise, Connoisseurship, and Experiential Knowledge in Professional Practice," Journal of Research Practice, vol. 11, no. 2. [Online]. Available: http://jrp.icaap.org/index.php/jrp/article/view/530/429 
[41] I. Nonaka and G. Von Krogh, "Perspective-tacit knowledge and knowledge conversion: Controversy and advancement in organizational knowledge creation theory," Organization science, vol. 20, no. 3, pp. 635-652, 2009.

[42] D. A. Schön, The reflective practitioner: How professionals think in action. New York, USA: Basic books, 1983, p. 384.

[43] P. M. Hildreth and C. Kimble, "The duality of knowledge," 2002.

[44] W. Wong and D. F. Radcliffe, "The tacit nature of design knowledge," Technology Analysis \& Strategic Management, vol. 12, no. 4, pp. 493-512, 2000.

[45] A. Petermans, K. Van Cleempoel, and J. Vanrie, "Tacit knowledge in interior architecture: interior architects on the designer-paying client-user client relationship," in Diversity and Unity. IASDR 2011, Delft, 2011.

[46] K. Niedderer and Y. Imani, "Developing a framework for managing tacit knowledge in research using knowledge management models," presented at the Undisciplined! Design Research Society Conference 2008, Sheffield, UK, 2009.

[47] D. H. Warren, "Perception by the blind," Perceptual ecology, vol. 10, p. 65, 1978.

[48] E. W. Hill, J. J. Rieser, M.-M. Hill, and M. Hill, "How persons with visual impairments explore novel spaces: Strategies of good and poor performers," Journal of visual impairment \& blindness, 1993.

[49] J. Herssens, "Designing for more: a framework of haptic design parameters with the help of people born blind (doctoral dissertation)," Faculty Architecture and Art, University of Hasselt KULeuven, Leuven, Hasselt, 2011. [Online]. Available: https://doclib.uhasselt.be/dspace/handle/1942/13903

[50] J. J. Rieser, "Development of perceptual-motor control while walking without vision: The calibration of perception and action," Sensory-motor organizations and development in infancy and early childhood, pp. 379-408, 1990.

[51] P. J. Stappers and E. B. Sanders, "Generative tools for context mapping: tuning the tools," in Design and Emotion, 2003.

[52] B. Lawson, "What Designers Know," ed. New York: Routledge, 2004.

[53] B. Lawson, How designers think. The Design Process Demystified, fourth ed. London: Architectural Press, 2005. 1980.

[54] A. Comi and M. J. Eppler, "Visual representations as carriers and symbols of organizational knowledge," in Proceedings of the 11th International Conference on Knowledge Management and Knowledge Technologies, 2011: ACM, p. 8.

[55] J. K. Whyte, B. Ewenstein, M. Hales, and J. Tidd, "Visual practices and the objects used in design," Building Research \& Information, vol. 35, no. 1, pp. 18-27, 2007.

[56] M. Perry and D. Sanderson, "Coordinating joint design work: the role of communication and artefacts," Design studies, vol. 19, no. 3, pp. 273-288, 1998. [Online]. Available: http://ac.elscdn.com/S0142694X98000088/1-s2.0-S0142694X98000088-main.pdf?_tid=6cbf2fa2-6cf9-11e58791-00000aacb360\&acdnat=1444225603_b9da7c837851cb1dfa8c4410d646ea0e http://www.sciencedirect.com/science/article/pii/S0142694X98000088.

[57] P.-W. Vermeersch, "Less Vision, More Senses. Towards a More Multisensory Design Approach in Architecture (doctoral dissertation)," 2013.

[58] R. Luck, "Using artefacts to mediate understanding in design conversations," Building Research \& Information, vol. 35, no. 1, pp. 28-41, 2007.

[59] B. Ewenstein and J. K. Whyte, "Visual representations as 'artefacts of knowing'," Building Research \& Information, vol. 35, no. 1, pp. 81-89, 2007.

[60] J. Herssens, M. Nijs, and H. Froyen, "Inclusive Housing (Lab) for All: a home for research, demonstration and information on Universal Design," presented at the International Conference on Universal Design, Lund, Sweden, 2014.

[61] R. K. Yin, Case Study Research: Design and Methods, 5th ed. London: Sage Publications, 2014.

[62] R. Luck and J. McDonnell, "Architect and user interaction: the spoken representation of form and functional meaning in early design conversations," Design Studies, vol. 27, no. 2, pp. 141-166, 2006.

[63] O. Pedgley, "Capturing and analysing own design activity," Design Studies, vol. 28, no. 5, pp. 463-483, 2007.

[64] B. Ewenstein and J. Whyte, "Knowledge practices in design: the role of visual representations asepistemic objects'," Organization Studies, vol. 30, no. 1, pp. 07-30, 2009.

[65] R. Luck, "Dialogue in participatory design," Design studies, vol. 24, no. 6, pp. 523-535, 2003. [Online]. Available: http://ac.els-cdn.com/S0142694X03000401/1-s2.0-S0142694X03000401main.pdf?_tid=7655de2c-6c2b-11e5-8a6c00000aab0f6b\&acdnat=1444137143_9a3745481c4814fe42d0579b4f28ec38. 
[66] M. Kouprie and F. Sleeswijk Visser, "A framework for empathy in design: stepping into and out of the user's life," Journal of Engineering Design, vol. 20, no. 5, pp. 437-448, 2009.

[67] L. Sanders, "ON MODELING An evolving map of design practice and design research," interactions, vol. 15, no. 6, pp. 13-17, 2008.

[68] R. Luck, "Learning to talk to users in participatory design situations," Design Studies, vol. 28 , no. 3, pp. 217-242, 2007. [Online]. Available: http://ac.els-cdn.com/S0142694X0700018X/1-s2.0S0142694X0700018X-main.pdf? tid=a770b478-6c2b-11e5-a70f00000aab0f6c\&acdnat $=1444137225 \_c 2 a 20552 \mathrm{e} 6 \mathrm{~b} 9320513 \mathrm{aa} 2 \mathrm{bc} 3 \mathrm{dc} 0 \mathrm{ef} 4 \mathrm{e} 8$ http://www.sciencedirect.com/science/article/pii/S0142694X0700018X.

[69] R. Luck, "Using objects to coordinate design activity in interaction," Construction Management and Economics, vol. 28, no. 6, pp. 641-655, 2010.

[70] N. Cross, K. Dorst, and H. Christianns, "Analyzing design activity," ed: Wiley West Sussex, 1996. 